\title{
Innovative Environment-Saving Technology Using Magnetic Sorbents Based on Carbon- Containing Waste from Coal
}

\author{
Elena Ushakova ${ }^{1 *}$, Ekaterina Kvashevaya ${ }^{1}$, and Andrey Ushakov $^{1}$ \\ ${ }^{1}$ T.F. Gorbachev Kuzbass State Technical University, 650000 Vesennyaya street 28, Kemerovo, \\ Russia
}

\begin{abstract}
One of the most effective methods of oil removal from the water surface is sorption with solid sorbents. The issue of oil sorption by magnetic sorbents based on carbon-containing waste from coal, woodworking and livestock enterprises is considered in the article. In the course of the experiments, the time of sorption equilibrium onset was determined, a sorption curve was constructed, and its form was determined. According to the study, it is revealed that the developed magnetic sorbents have a maximum oil capacity of $3 \mathrm{~g} / \mathrm{g}$ and show a high affinity for oil.
\end{abstract}

\section{Introduction}

According to data of British Petroleum, the world leader in the oil production rating is Russia - about 10.11 million barrels per day, followed by Saudi Arabia - 9.73 million barrels per day. The three leaders top finish the US 8.65 million barrels per day [1].

The constant growth of oil production and its processing does not allow to consider this branch as an ideal production. The number of oil spills emergencies is constantly growing, so the pollution of water bodies, both crude oil and products of its processing today is a matter of serious concern. Oil and its constituents are one of the most dangerous substances, most of which are poisonous to any living organisms [2].

For today, oil sorbents from natural raw materials of vegetable and animal origin receive and based on waste from their processing a wide distribution: sawdust [3, 4], dried grain products [5], husk [6], wool [7], peat [8] and over.

Most of oil sorbents do not always meet the high requirements of oil spill response. Because the sorbents are light enough and they have sail, they are difficult to apply: to insert and collect. Even after saturation with oil, they are able to quickly move under the influence of wind and currents. That is why magnetic properties of sorbents makes it possible to increase the efficiency of their use due to the possibility of controlling them on the water surface. In the case of using magnetic sorbents, it becomes possible to direct the sorbent to places of high contamination concentration. Thus, the maximal working out of the sorbent is reached.

* Corresponding author: ushakovaes@kuzstu.ru 
In modern science, the sorption properties of various sorbents has been studied in detail. However, the study of magnetic sorbents remains insufficiently studied.

At the department of Chemical Technology of Solid Fuel KuzSTU proposed a method of obtaining oil sorbent from secondary raw materials, namely animal husbandry (manure, manure) and carbonaceous waste woodworking (sawdust, shavings, flour) and coal industry (coal/coke breeze, dust, sludge), excess active sludge of biological treatment facilities with the use of the magnetic component - magnetite [9].

The technology for obtaining magnetic sorbents includes the process of anaerobic treatment of the binder (animal waste, excess active sludge); mixing with filler and magnetite; granulation and pyrolysis under certain conditions.

The purpose of this work is to study the kinetic and thermodynamic parameters of the sorption process of oil by magnetic sorbents from the water surface.

\section{Materials and Methods}

To simulate a spill of petroleum products in water bodies, a $200 \mathrm{ml}$ tank filled with $50 \mathrm{ml}$ of distilled water was used. Crude oil was used as the contaminant component with an initial concentration in water of $0.1 \mathrm{~g} / \mathrm{ml}$. The sorption process was carried out at a temperature of $298 \mathrm{~K}$.

A single-stage static sorption method was used in the work. The experiment was carried out by adding the oil sorbent to the studied emulsions, so that it was located at the water:oil interface. Every 10 minutes, the sorbent was removed, dried at a temperature of $45{ }^{\circ} \mathrm{C}$ (to prevent the large volatilization of petroleum products), and the amount adsorption was determined from equation $(\mathrm{g} / \mathrm{g})$ :

$$
C_{i}=\frac{m_{i}}{m_{\text {sorb }}}
$$

where $m_{i}$ - mass of the absorbed component, $\mathrm{g}$;

$m_{\text {sorb }}$ - mass of sorbent taken for testing, $\mathrm{g}$.

The residual oil concentration $[\mathrm{g} / \mathrm{ml}]$ in water was determined by equation (2):

$$
C_{\text {res }}=\frac{C_{0} V-M}{V}
$$

where $C_{0}$ - initial oil concentration in water, $\mathrm{g} / \mathrm{ml}$;

$V$ - the oil:water volume used in the experiment, $\mathrm{ml}$;

$M-$ mass of sorbed oil, g.

\section{Results and Discussion}

To determine the optimal conditions for the sorption of petroleum products by the sorbent, a kinetic curve has been constructed (Fig. 1).

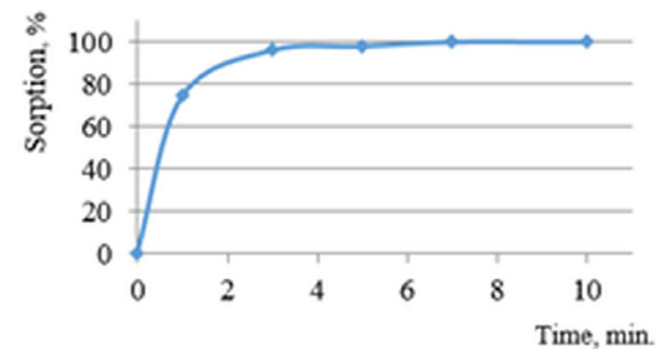

Fig. 1. Sorption kinetic of oil by a magnetic sorbent. 
When the sorbent is placed on the water surface, the main sorption, more than $80 \%$, is manifested during the first 2 minutes, then the sorption changes insignificantly. The complete oil sorption occurs after a 7-minute interaction of the sorbate with the adsorbent, that is, sorption equilibrium sets in.

The presence of a linear dependence of the sorption-the time during the first 2 minutes indicates the high adsorption capacity of the developed sorbent to oil products. Visually there is no stage responsible for sorbent wetting with the oil on the graph, i.e. the sorbent as soon as it touches the oil begins to sorb it.

This phenomenon is most likely due to the magnetite; based on literature data, magnetite is readily soluble in petroleum products [10]. As a proof of the theory, the oil adsorption curve by sorbents of similar composition, but without the introduction of magnetite in them (Fig. 2).

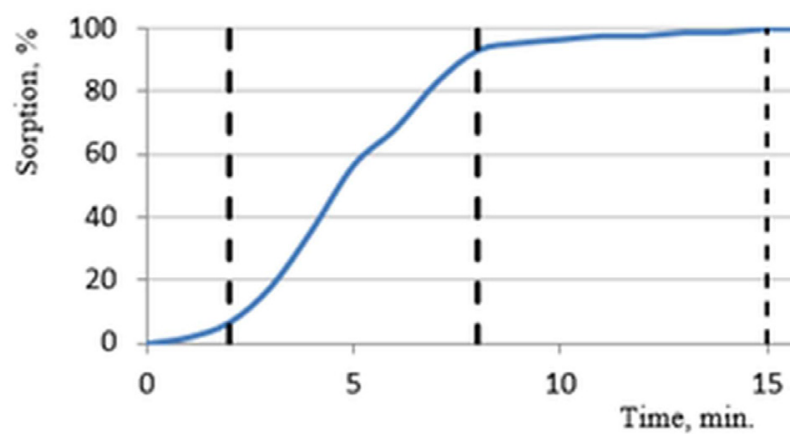

Fig. 2. Sorption kinetic of oil by a sorbent without magnetite.

If using granules without magnetite for sorption, a wetting zone 0-2 minutes appears, and sorption of $85 \%$ is reached only in 7 minutes.

A comparison of the literature and the obtained data allowed to draw the following conclusion: during the sorption, an internal diffusion plays the important role in the time interval up 2 to 7 minutes, causing oil to penetrate deep into pores of sorbent structure that are accessible in size. It is allow the oil product to be sorbed again on the external surface of the sorbent. Due to this fact that the first stage sorption is $80 \%$, so the second sorption stage is already not mandatory, i.e. the duration of phase contact is a parameter that has little effect on the sorption efficiency of the developed sorbent. This fact means that the magnetic oil sorbent can be used not only under static conditions, but also dynamically, for example, when emulsions filters through the sorbent mound in the apparatus or in the case of creating a floating filter on water bodies with a strong current.

The basic information about the sorption properties and the nature of the petroleum products adsorption can be obtained from adsorption isotherms characterizing the dependence of the sorption properties $(G)$ on the concentration $(C)$ of the sorbed component at a constant temperature: $T=f(C)$.

To construct the sorption isotherm, the sorption of petroleum products $(\mathrm{G})$ was found from formula (3)

$$
G=\frac{\left(C_{0}-C_{r e s}\right) \cdot V}{m_{\text {sorb }}}
$$

where $C_{0}$ - the initial oil concentration in water, $\mathrm{g} / \mathrm{ml}$;

$C_{\text {res }}$ - the residual oil concentration in water, $\mathrm{g} / \mathrm{ml}$;

$V$ - the oil:water volume used in the experiment, $\mathrm{ml}$;

$m_{\text {sorb }}$ - mass of sorbent taken for testing, $\mathrm{g}$. 
The obtained data were used to construct the sorption isotherm at $298 \mathrm{~K}$, presented in Fig. 3. At the same time, the equilibrium concentrations $C_{e q}$ are numerically equal to the values of $C_{\text {res }}$ at the same amounts of sorbent (Fig. 2).

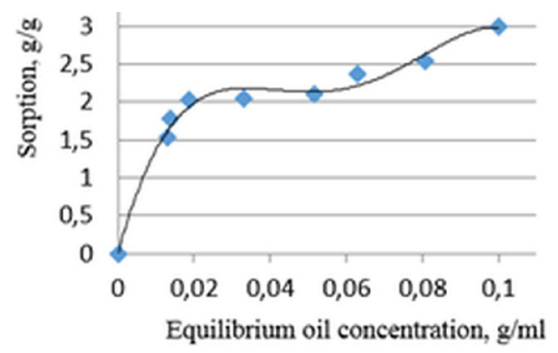

Fig. 3. Sorption isotherm of oil by the sorbent.

Thus, with increasing the total oil concentration, the adsorption amount increases, the oil molecules in the adsorption layer converge and form a saturated layer, so the adsorption increases.

As can be seen, in the region of very low concentrations the isotherm curve intersects the ordinate axis. According to Gill's classification, this curve can be assigned to class L-3 (Langmuir isotherms). The isotherms of this class are bent relative to the concentration axis, which indicates a strong adsorption energy. According to the curve, the adsorption continues after saturation of the monolayer. As a result, the oil sorbent particles coated with oil are able to form agglomerates. In addition, between the sorbent and the petroleum product, there is a possibility of insignificant chemical interactions (chemisorption).

The general rule: the better this solvent (in this case water) wets the adsorbent, the less adsorption of the dissolved substance (in this case oil) and vice versa. The adsorption of solute on a solid surface will be the greater, the greater the polarity difference between the solvent and the adsorbent, and vice versa. In this case, the polarity difference between the sorbent and oil is less than that between the sorbent and water.

By the Langmuir equation, the value of the adsorption constant can be determined. In practice, the linear form of the Langmuir equation is used to analytically describe the monomolecular adsorption isotherm:

$$
\frac{C_{e q .}}{A}=\frac{1}{A_{\text {пр. }}} C_{e q}+\frac{1}{\mathrm{~A}_{\text {пр. } \mathrm{k}}}
$$

where $A$ - the specific adsorption, $\mathrm{g} / \mathrm{g}$;

$A_{\text {lim }}$-the limiting adsorption, $\mathrm{g} / \mathrm{g}$;

$C_{e q .}$ - equilibrium oil concentration, $\mathrm{g} / \mathrm{ml}$;

$\mathrm{k}$ - adsorption equilibrium constant, $\mathrm{ml} / \mathrm{g}$.

Equation (4) is the straight line. From the experimental data, we plot the graph of $C / A$ $=f(C)$ and perform its linear approximation (Fig. 4).

Because of the experimental data, it was established that the limiting adsorption, which means a complete monomolecular coating of the adsorbent by adsorbate molecules on a magnetic oil sorbent is $3 \mathrm{~g} / \mathrm{g}$. The absence of a free term in the equation probably proves that the sorption activity of the sorbent does not depend on external factors (temperature, mixing, etc.), but is caused only by the equilibrium concentration of oil. 


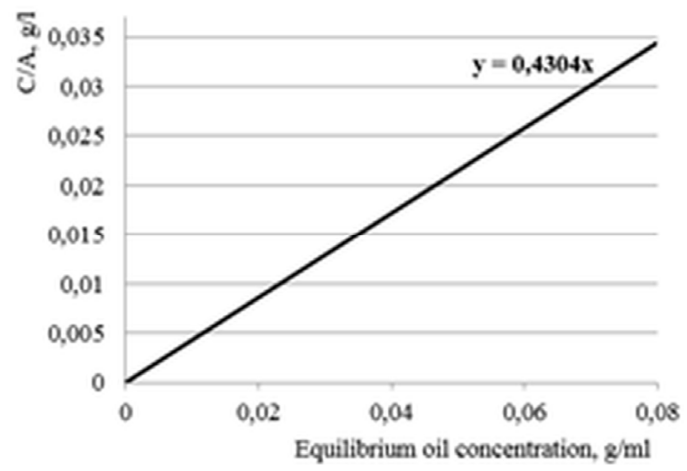

Fig. 4. The graphical representation of the linear form of the Langmuir equation for the oil sorption by the oil sorbent.

It is necessary to note some special moments of the experiments. Despite the fact that the drying of the sorbent granules was carried out at low temperatures, the evaporation of petroleum products was still observed, since the samples of the used oil contain an easily volatile gasoline fraction. Therefore, the refining of petroleum products amounted to $22 \%$ of the initial amount if using drying oven at $45^{\circ} \mathrm{C}$.

\section{Conclusion}

In connection with the high affinity of the developed magnetic sorbent and oil, sorption is observed immediately after contact. While the sorbent holds the oil product firmly, not allowing it to spread out over the water. Thus, the investigated oil sorbent can be used not only in static, but also in dynamic types of sorption. The maximum oil capacity of the sorbent is $3 \mathrm{~g} / \mathrm{g}$.

\section{References}

1. BP Global Energy economics (Statistical Review of World Energy, London, 2017)

2. I. Aleshin. Environmental Protection in the Development of World Ocean Resources (SPbGMTU, St. Petersburg, 2005)

3. F. Kamenshchikov, E. Bogomolny, Removal of oil products from the water surface and soil (R \& C Dynamics, Izhevsk, 2006)

4. S. Tsyganova, E. Veprikova, E. Tereshchenko, O. Fetisova, Ecology and Industry of Russia, 6, 18 (2014)

5. A. Myakinkov. Food and processing industry, 4, 1407 (2000)

6. Sh. Nursetov, S. Ospanov, A. Prnazarova, B. Temir, Science and Peace, 2, 66 (2016)

7. I. Shaikhiev, R. Nizamov, A. Shmykov. Environmental protection in the oil and gas sector, 3, 9 (2008).

8. L. Novoselova, E. Sirotkina, Chemistry of Solid Fuels, 4, 64 (2008)

9. E. Kvashevaia, E. Ushakova, A. Ushakov, The Second International Innovative Mining Symposium, 21, 01003 (2017)

10. E. Bryukhanova, A. Ushakov, G. Ushakov, International Scientific and Research Journal, 3, 47 (2013) 